This is the author's final, peer-reviewed manuscript as accepted for publication. The publisher-formatted version may be available through the publisher's web site or your institution's library.

\title{
Rethinking distance learning activities: a comparison of transactional distance theory and activity theory
}

Haijun Kang and Allan S. Gyorke

\section{How to cite this manuscript}

If you make reference to this version of the manuscript, use the following information:

Kang, H. \& Gyorke. A. (2008). Rethinking distance learning activities: A comparison of transactional distance theory and activity theory. Retrieved from http://krex.ksu.edu

\section{Published Version Information}

Citation: Kang, H. \& Gyorke. A. (2008). Rethinking distance learning activities: A comparison of transactional distance theory and activity theory. Open Learning, 23(3), 203-214.

Copyright: @ 2008 The Open University

Digital Object Identifier (DOI): DOI:10.1080/02680510802420050

Publisher's Link: http://www.informaworld.com/openurl?genre=article\&issn=02680513\&volume $=23 \&$ issue $=3 \&$ spage $=203$

This item was retrieved from the K-State Research Exchange (K-REx), the institutional repository of Kansas State University. K-REx is available at http://krex.ksu.edu 


\title{
Rethinking distance learning activities: a comparison of transactional distance theory and activity theory
}

Haijun Kang* and Allan S. Gyorke

\begin{abstract}
Despite its invaluable guidance to distance education development, transactional distance (TD) theory is not seamlessly synchronised with current field practice and lacks a social component. After it has provided over 30 years of guidance, there is now a need to re-appraise TD's propositions about distance learning activities. The social-cultural aspects of the distance learner need to be highlighted because social learning is prominent in today's practice. To address this concern, we compared TD with a social science theory - cultural-historical activity theory. This cultural-historical activity theory provides a different lens for us to explore distance learning activities - a social lens. We compare the major concepts of the two theories and illustrate some areas of compatibility. We explore the contradictions that arise from the collision of these two theories and recommend future directions for research.
\end{abstract}

Keywords: transactional distance; interaction; activity theory; mediation; artefact; activity

\section{Introduction}

For over 30 years Moore's transactional distance (TD) theory has helped to identify and distinguish distance education as an academic discipline, and has provided a broad pedagogical framework for studies of distance learning activities. Reviewing its current development, however, we have noticed that the theory has missed the social characteristics of distance learners that are so important in today's practice.

From the late twentieth century, distance education has entered into its post-modern development phase (Saba, 2007) and has shifted from a structural paradigm to a transactional

\footnotetext{
* Corresponding author. Department of Educational Leadership, Kansas State University Email: hjkang@ksu.edu
} 
paradigm (Garrison, 2000). Particularly after the occurrence of social software (blog, wiki, twitter, MySpace, YouTube, social bookmarking, etc.) and the rapid development of modern communication technologies (Web 2.0, Mobile, Wi-Fi, etc.), individual learners have been empowered with more control over what to learn, how to learn, when to learn and how much to learn. This maximisation of learners' control over their learning activities needs to be recognised and continuously stressed in the development of modern distance education theory.

The purpose of the present paper is to address this issue by comparing TD with a social science theory - cultural-historical activity theory (CHAT). The reason we chose CHAT is because of its focus on social aspects of human behaviour and its richness in comprehending the full range of human activity. CHAT theorists stress the social features of human beings and believe that human development is based on a series of interactions with one's social and cultural context. Applying this to distance learning activities, it is very evident that a learner is a social being and that learner development is based on a series of interactions with one's learning context. This interplay between the learner and learning context is also TD's focus. TD is the psychological and communication space between physically separated teachers and learners. Learner development is based on the bridging of this gap 'through distinctive procedures in instructional design and the facilitation of interaction' (Moore \& Kearsley, 2005, p. 223).

In the paper we start with a short background on TD and CHAT to set up an introduction for our in-depth discussion and comparison of the major concepts of both theories.

\section{Transactional distance theory}

TD theory has been recognised by the field as a seminal concept that provides a broad framework for distance education pedagogy. The idea of TD was first introduced into the field in the early 1970s by Moore (1972), and has been widely used to guide practice and research since then. The significance of TD theory, according to Moore, is that it 'allows the generation of an almost infinite number of hypotheses for research into the interactions between course structures, dialogue between teachers and learners, and the student's propensity to exercise control of the learning process' (2007, p. 101). The theory success- fully claimed the unique identity of 
distance education and showed that the distance caused by the physical separation of learners and teachers should be understood pedagogically.

To further stress its pedagogical essence, Moore named the theory 'transactional distance' (Moore, 1980, p. 19). The term 'transaction' was derived from John Dewey, developed by Boyd and Apps, and recontextualised by Moore to the distance education field. A concise depiction of the concept 'transactional distance' can be found in his book Distance Education: A Systems View (second edition):

The transaction that we call distance education is the interplay between people who are teach- ers and learners, in environments that have the special characteristic of being separate from one another. It is the physical distance that leads to a communication gap, a psychological space of potential misunderstandings between the instructors and the learners that has to be bridged by special teaching techniques; this is the 'Transactional Distance' (Moore \& Kearsley, 2005, p. 224)

According to Moore (1983, 2007; Moore \& Kearsley, 1996), TD is determined by three factors and three variables. The three factors are teacher, learner, and a means of communication. The absence of one of these factors would lead to an absence of TD because 'there can be no educational transaction!' (Moore \& Kearsley, 1996, p. 200). The degree of TD depends on three variables: dialogue, structure, and learner autonomy. Dialogue describes the exchange of words, actions, and ideas between teacher and learner, the nature and extent of which are determined by the educational philosophy of institutions, by the characteristics of individuals involved in the interaction, by the content or subject matter, and by environ- mental factors. A very important factor that affects dialogue is the means of communication. Structure is a measure of the extent to which a course's elements, such as learning objectives, content themes, presentation strategies, and evaluation activities, change to meet the specific needs of individual learners. Note that a high measure of structure indicates that a course is rigid and cannot easily adapt to each learner. On the continuum of dialogue (D) and structure (S), Moore (1983) classified four categories of programmes $(-\mathrm{D}-\mathrm{S},-\mathrm{D}+\mathrm{S},+\mathrm{D}+\mathrm{S},+\mathrm{D}-\mathrm{S})$ that indicate the presence or absence of dialogue and structure in educational systems. He also hypothesised the relationship between dialogue, structure and TD: 'As dialog increases, transactional distance decreases; ... As structure increases, transactional distance also increases' (Moore, 2007, p. 
94). Learner autonomy is the theory's third variable. Literally, learner autonomy means a learner's control over learning activities and processes. Great TD requires high learner autonomy. According to Moore (2007), there is no absolute learner freedom and excessive learner freedom is also not desirable. The final decision about how much learner freedom is appropriate should be made by each programme. The extent of dialogue, the level of structure and the degree of learner autonomy varies largely from programme to programme and from institution to institution.

Being intrigued by the idea of TD, subsequent researchers have conducted various studies to extend and adapt Moore's TD theory. There are studies - such as Saba (1988) and Saba and Shearer (1994) - that focus on the verification of the validity of the theory, of its propositions, and of the relationships between the theory's major constructs. There are studies that create or adapt from other researchers instruments to measure transactional distance and its relationship with learner satisfaction and learning outcomes - examples include Bischoff (1993), Dron (2002), Dron, Seidel, and Litten (2004), Pruitt (2005), Stein, Wanstreet, Calvin, Overtoom, and Wheaton (2005), and Wikeley and Muschamp (2004). There is also research that focuses on individual constructs. Each construct is broken down into smaller units of analysis to evaluate its validity and effectiveness, such as has been done by Hillman, Willis, and Gunawardena (1994), Anderson and Garrison (1998), Wagner (1994), Anderson (2003), Woods and Baker (2004), and Gorsky, Caspi, and Trumper (2004). The last group of studies attempted to expand the idea of TD by postulating new concepts and bringing new factors into discussion. For example, Shin (2001) and Shin and Chan (2004) researched distance learners' perceptions of 'transactional presence'; Garrison (2000) and Dron $(2006,2007)$ postulated the concept of 'transactional control'; and Lowell (2004) made a connection between TD and a student's social presence.

While acknowledging the great contribution TD theory has made to the field and to our understanding of the TD phenomenon, we argue that the theory's development process gets bogged down in terms of its interplay with social and global contexts. After 30 years, we are still circling around TD's three constructs: structure, dialogue and auton- omy (Dron, 2007; Garrison, 2000; Gorsky and Caspi, 2005). Researchers' creativities have been constrained by the well-structured box TD set up a long time ago. While thinking inside the box is necessary to make this theory as robust as possible, being addicted to the inside of the box and ignoring its environment becomes very risky. As Gorsky and Caspi pointed out, 
empirical studies that attempted to support the TD theory are actually leading the theory to be construed as tautologous: 'As understanding increases, misunderstanding decreases' $(2005$, p. 8). Therefore, there is a need to re- appraise the TD theory and its propositions in today's global socialisation context. To do so, we need to especially highlight the socialcultural aspects of the distance learner as social learning is a major theme of today's academic life. The comparison of the TD theory and the CHAT theory that follows our brief introduction to the CHAT theory serves this purpose.

\section{Activity theory}

Initiated by a group of Russian psychologists in the 1920s and 1930s and recontextualised by western researchers after the 1970s, the cultural-historical theory of activity (CHAT) has been developed to enrich our understanding of the individual and societal aspects of human behaviour (Tolman, 1999). CHAT has experienced three generations. Lev Vygotsky represented the first generation, in his attempt to unify behavioural science with 'Marx's theory of society (known as historical materialism)' (Cole \& Scribner, 1978, p. 7).

Vygotsky adapted the concept of mediation from Marx's dialectical and historical materialism. He claimed that instead of a behaviourist model of individual stimulus and response, human development is based on a series of interactions with one's social and cultural context, which are mediated by tools and signs. Alexei Leont'ev expanded Vygotsky's idea by addressing the distinction between collective activity and individual activity (Leont'ev, 1978). Leont'ev's notion of activity, action, and operation provides a visual structure of complex human activity, and is the most significant product of CHAT's second generation. CHAT's third generation dealt with the incorporation of the full range of human activity. Engeström, one of the leading figures in the field, has been working on models of activity systems since 1987. He developed a new pyramidal model of activity systems. This model not only reflects both collective and individual features of human activity, but also incorporates the intersubjective components that arise in the context of artificial objects.

Artefacts and mediation are two major concepts within CHAT. Artefacts have a decisive influence on human activity through the mediation process. Vygotsky (1978) makes a clear distinction between two types of activities mediated by different artefacts: tool-mediated labour and sign-mediated psychological activity. Tool-mediated labour is intended to control the outside 
world while sign-mediated psychological activity is to regulate one's thoughts, memory, and affecting behaviour. 'The tool's function is to serve as the conductor of human influence on the object of activity ... it must lead to changes in objects ... The sign ... is a means of internal activity aimed at mastering oneself' (Vygotsky, 1978, p. 55). Even though one is used in the process of internalisation and the other is used in the process of externalisation, both artefactmediated processes are reciprocally connected. Engeström pays great attention to mediation because it is a 'unifying and connecting lifeline throughout the works of Vygotsky, Leont'ev, Luria, ...' (1999, p. 29). Like Vygotsky, Engeström states that the creation and use of tools is a way to transmit accumulated social knowledge. Under- standing artefacts and mediation will help us perceive the continuity between psychic processes and activity.

Researchers using empirical techniques in the pursuit of 'scientific truth' search for explanatory factors from two sources: person and environment. They separate those factors into two categories (independent variables and dependent variables) and explain human action by examining the correlations between them. One valuable feature of CHAT is its capability of explaining human action by incorporating a third source - activity, which 'transcends the person-environment dichotomy' (Eskola, 1999, p. 109). In CHAT, activity takes the primary position amongst these three sources: CHAT researchers explore people's activity before searching for factors from people and the environment. As Eskola says,

'[activity] is the first thing we have to realize; only then can we see whether there is any room left for additional explanations referring to person and environment' (1999, p.109).

The activity system model proposed by Engeström (1999) is used by researchers to map the explanatory factors that are discovered from activity, people, and environment. This model shows the activity of subjects on an object, mediated through artefacts, interacting with a community, moderated by a set of rules, and distributed by a division of labour. Each of these pieces of the activity system interacts with the others (see Figure 1).

In summary, the TD theory identifies and explains transactional distance caused by the physical separation of teachers and learners. It has three major components (student, teacher, and means of communication) and three fundamental variables (structure, dialogue and learner autonomy). The means of communication play a critical role between the three components as 
well as the three fundamental variables. Although TD theory has provided valuable guidance to the field for the past three decades, it has failed clearly to incorporate the concept of social learning that has been identified as a critical feature of today's practice. The CHAT theory, on the contrary, has a strong focus on the social aspects of human beings. CHAT theorists claim that cultural and historical contexts play an important role in the formation of each artefact-mediated activity and that artefact-mediated activity constitutes the main source for the explanation of human activity; it links psychological processes with human being's external behaviour. In the following sections, we compare the major concepts of the two theories, illustrate some areas of compatibility and explore the contradictions that arise.

\section{Discussion}

In both theories, mediation and participation in an activity (or system) are often discussed. However, the nature of these concepts is fundamentally different within each theory. We believe these contradictions are valuable as the basis for future research questions that seek to expand the TD theory.

\section{Mediation: devices versus artefacts}

The term 'mediation' is used in both theories; however it would be a mistake to ignore the differences in their use. TD originated from a discussion of the distinguishing features that separate face-to-face education from modes of distance education. The difference is identified in Moore's (1972) discussion of transactions in distance education, which states that the teaching and learning behaviours are separated, so communication between teacher and learner must take place through physical devices. Keegan (1990) echoes this reliance on physical devices as one of his criteria for defining distance education, which he argues is: 'the use of technical media - print, audio, video, or computer - to unite teacher and learner and carry the content of the course' (Keegan, 1990, p. 44). From this point of view, these physical devices mediate the interactions between teacher, student, and content. As an example of the use of the term 'mediation' in this context, the phrase 'computer-mediated communication' is understood to mean that computers are the specific technology used to bridge the separation between learner and teacher. TD distance is influenced by the extent to which the use of these devices within a distance education course permits the learner to communicate with and receive a response from the teacher and other learners (Moore, 1983). 
Using these definitions, language is not included as a 'device' that mediates communication, primarily because language is not a differentiating factor between face-to-face and distance education. In other words, since written and spoken language are used in both types of educational systems, discussions of language as a device are more a part of the general field of education rather than the specialised field of distance education. In recent publications and field practice, however, language is always evidenced to be problematic in discussions of distance learners' differences such as gender, national culture, and native language of participants (for example, Goodfellow, Lea, Gonzalez, \& Mason, 2001; Kramarae, 2003; Shattuck, 2005). The discussion of national culture and language differ- ences is especially important in today's distance education because of its potential to reach participants around the globe. With this respect, CHAT has done a better job and gives language great attention while discussing mediation as a human subject-related activity.

Within CHAT, mediation is present in all human activity, even when the participants are acting in the same geographical location at the same time - and even when there is no teacher. The idea of mediation originates with Vygotsky's (1978) investigation into the uniquely human use of signs and tools that are used to extend human abilities to control their environments and themselves. For example, the social development of simple writing allowed humans to extend memory by exceeding individual psychological limitations and evolving to elaborate culturallyembedded behaviours (Vygotsky, 1978). Vygotsky made a distinction between tools, which are objects that exert human influence on objects, and signs, which are created to control human behaviour.

From the perspective of CHAT, it would not be sufficient to merely extend the idea of mediation in transactional distance to include language. The idea of a mediating artefact goes well beyond the conception of a mediating device through which communication between student and teacher is conducted. According to Engeström, mediation by tools and signs 'breaks down the Cartesian walls that isolate the individual mind from the culture and the society' (1999, p. 29). In CHAT, artefacts are ubiquitous: anything that is used within an activity system is potentially an artefact (sign or tool). Within the system, the meanings of signs and use of tools are constructed as a culture develops over time (Cole, 1999) and have an organising effect on human thought (Vygotsky, 1978). 
If we apply CHAT's use of mediation to TD, it creates an opportunity to explore contradictions that arise. Certainly computers, telephones, and videotapes are mediating artefacts since they are tools used for presenting information and permitting dialogue between people who are separated. But the course content and dialogue between learner and teacher, and between learner and learner (such as student questions and assignments, instructor encouragement and feedback), are also mediating artefacts when they are used in the educational process. This is important when looking at the nature of dialogue and human agency within TD. Dialogue permits an exchange of ideas between learners, learners and teachers. Through dialogue, the learner can participate in the construction of meaning. Without dialogue, the learner is positioned as a recipient of pre-existing knowledge that has been formulated entirely by the teacher and/or a community of experts. From the perspective of TD, courses delivered through television transmission are considered to have high structure and no dialogue since they cannot be easily changed to meet the needs of an individual learner and do not permit a learner to obtain a response from the teacher (Moore, 1983). This leads to some interesting questions. Could structure be defined as the extent to which the teacher creates course artefacts without input from the learners? Does this pre- determined nature of artefacts make the 'transmitted' knowledge more difficult to internalise? Or, to put it differently, are learners more easily able to internalise knowledge that they helped to create through shared activities with a teacher or other students? Obviously, how we treat the role that artefacts (including language) play in distance teaching/learning process has a significant impact on our judgement of transactional distance. This difference between TD's view of device-based mediation versus CHAT's view of artefactmediated communication is worth exploring further.

\section{Participation: interactions versus activity}

A discussion of mediation alone would be incomplete without also looking at the way mediation is used. TD focuses on interactions between participants who are separated by distance. In CHAT, the focus is on the mediated nature of all aspects of human activity.

Moore (1989) identified three basic types of interaction: student-teacher, studentstudent, and student-content. The nature of a student-teacher interaction can be understood through an analogy of a tennis pro and her student practising on a tennis court. The ball, rackets, and court are the technologies used to exchange communication between the two participants. 
Ideas, assignments, and feedback are passed back and forth between them in a turn-taking manner, with the goal of coaching the student to a higher level of playing ability. Likewise, student-student interaction can be modeled as two people who are both trying to improve their abilities. Finally, student-content interaction could be a student reading about tennis, watching a videotape of professional players, or (in the case of computer-based tutorials) a student practising hitting balls hurled from an automated tennis ball machine.

Others have expanded upon Moore's three original types of interactions, including Hillman et al. (1994), Burnham and Walden (1997), Anderson and Garrison (1998), and so forth. While this discussion of the many types of interactions that are present within a distance education system begins to drift further away from the original idea of the psychological distance between student and teacher, these ideas are very interesting when modeled together and compared with models of activity systems. Figure 2 is adapted from Anderson and Garrison (1998), but also includes an interpretation of the learner-interface and learner-environment interactions proposed by Hillman et al. (1994) and by Burnham and Walden (1997), respectively. In the figure, each double-ended arrow signifies an inter- action between parts of the distance education system. The small circular arrows signify student-student, teacher-teacher, and content-content interactions.

Since this model is specific to distance education, there is no specific teacher-environment interaction because the environment in this model is the student's environment. Certainly the teacher has an environment of his or her own, but that environment is distinguishable, if not separate, from the environment of the student.

In contrast to isolated interactions that have been studied as part of TD, CHAT focuses on human activity in a qualitatively different manner. To go back to the tennis analogy, instead of focusing on a student's exchange with a tennis pro or use of a racket and ball, CHAT would focus on playing tennis within a specific socio-cultural position. This focus permits an examination of the whole interconnected activity, which is composed of interactions between people and objects, but also includes an acknowledgement that these components change each other during the process of the activity. From the perspective of CHAT, knowledge and activity are very practical and situated. The knowledge of tennis and ability to change the nature of 
tennis and tennis players is all embedded within the Lebensform ('form of life') of playing tennis (Toulmin, 1999). Also, as mentioned above, the activity must be examined within its sociocultural position (Tolman, 1999). Certainly the Lebensform of playing tennis in a neighbourhood playground in Canada is different from playing tennis in a country club in the United States or playing tennis on the courts at Wimbledon.

Returning to the idea of distance education courses, we can try to model the activity system of 'learning', but that would be difficult to define without more information about what is being learned, who is learning it, who is teaching, and so on. Fortunately, Sawchuk, Gawron, and Taylor (2002) have applied CHAT to their study of the use of e-learning systems to teach union mobilisation to labour activists in Canada. In their system, they emphasised the importance of the relationships between learner-educator, learner-union, and educator-union. These relationships are somewhat similar to the interactions defined within distance education, except that they place more emphasis on the importance of the practical, social and cultural development of this educational system. The presence of the union and the particular study of union mobilisation is not merely an individual consider- ation. Those factors are the very reason that this system exists, and therefore any attempts to model the system only make sense when those relationships are included.

To create a graphical representation of this particular online activity system we chose an adaptation of a model proposed by Engeström (1999). In this model, six aspects of an activity system are identified and positioned with arrows to indicate their influence on each other. In Figure 3, we have mapped Sawchuk et al.'s (2002) CHAT-based study to this model. The mapping of an activity system to this type of model will largely depend on the activity in question. In this case, the activity being studied was distance-learning-based union mobilisation by labour activists. This activity is enabled through the use of a typical distance learning system including teachers, web sites, techniques, and so forth. With this focus, fellow workers, the union officials, and employees are indirect participants since they are not in the actual online course. Therefore we have placed the teachers as artefacts and other people as part of the community.

This model bears a resemblance to the model of interactions presented in Figure 2; however, there are some important contradictions. In Figure 2, there is little mention of the specific underlying parameters that guide the interactions (such as rules, division of labour, and 
outcome that are present in CHAT). These missing elements contribute largely to the structure of the course, whereas the elements that have been included in Figure 2 contribute more to the dialogue and learner autonomy within the course. However, these distinctions are not clear-cut, especially if considered from the lens of CHAT. For instance, rules are intended to guide behaviour (increase structure), but they can also be changed through actions (increase dialogue); actions are the negotiation of the control over the activity system (increase learner autonomy). Likewise, the relationships between participants (learner autonomy) would not be possible without the use of some socially constructed mediating artefacts (structure) and through certain actions (dialogue). In short, structure, dialogue and autonomy are reciprocally connected. They are contradictory and complementary - meaning that they are in a constant tension with each other, yet rely upon each other to remain part of a cohesive ongoing activity.

Another problem that can be seen in Figure 2 is the absence of the individual differences of the distance learner. Although the specific label 'individual differences' is not used in Figure 3 , it is understood in the literature that the rules the student follows, the community the student lives in, and the division of labour the student is involved in are the factors that formulate individual differences. As Tolman writes, 'The individual is society manifested in a single organism' (1999, p. 82). Granted, union workers are partially products of union society, but they may also be part of French Canadian society and Afro Canadian society and gay society as well. This is especially true in distance education, where students are more likely to be living within different national cultures and have different societal institutions, which Tolman states are the carriers for 'information required by individuals for functioning in society' (1999, p. 72). This difference between TD's view of an isolated individual versus CHAT's view of a communal individual that is a product of a multi- society is worth exploring further.

\section{Conclusion}

The present paper identified, interpreted, and compared several variables that lie between TD and CHAT. In TD, the term 'mediation' is used to represent the communications mediated by physical devices but language is not counted as a 'device'. In CHAT, however, mediation has a broader scope, and language has gained great consideration as an important social 'device' labelled as an artefact within any human activity system. While interaction typology is a critical spotlight of the TD theory, CHAT's tool-mediated and sign-mediated nature of all aspects of 
human interactions makes more sense with regard to the concept of social learning interaction.

By applying CHAT to distance education, this paper also explored the tentative relationships among the fundamental concepts of TD theory. We adapted previous models to provide a more complete picture of different interactions involved in the interconnected human activities in the context of distance education. Further, we adapted a CHAT model so we could examine the cultural-historical aspects of a particular online distance education system. Our understandings are that structure, dialogue and autonomy - the three major constructs of the TD theory - are contradictory and complementary; in contrast to CHAT's view of a communal individual, TD isolates learners from their multi-society contexts.

To further explore the intersection of TD and CHAT, we need to continue to analyse additional cases of online activity from the perspectives of both theories. It is our hope that this will lead to a newly refined TD theory.

\section{Acknowledgements}

Thanks to our Pennsylvania State University faculty, Dr Michael G. Moore and Dr Ian Baptiste, for providing sagacious feedback on this article.

\section{References}

Anderson, T. (2003). Modes of interaction in distance education: Recent developments and research questions. In M.G. Moore \& W.G. Anderson (Eds.), Handbook of distance education (pp. 129-144). Mahwah, NJ: Lawrence Earlbaum Associates.

Anderson, T., \& Garrison, D. (1998). Learning in a networked world: New roles and responsibili- ties. In C.C. Gibson (Ed.), Distance learners in higher education: Institutional responses for quality outcomes (pp. 1-8). Madison, Wisconsin: Atwood Publishing.

Bischoff, W.R. (1993). Transactional distance, interactive television, and electronic mail communi- cation in graduate public health and nursing courses: Implications for professional education. Unpublished doctoral dissertation, University of Hawaii, Honolulu, HI.

Burnham, B., \& Walden, B. (1997). Interactions in distance education: A report from the other side. Paper presented at the Proceedings of the Adult Education Research Conference, Oklahoma State University. Retrieved May 10, 2007, from http://www.edst.educ.ubc.ca/aerc/1997/ 97burnham.html.

Cole, M. (1999). Cultural psychology: Some general principles and a concrete example. In Y. 
Engeström, R. Miettinen, \& R. Punamaki (Eds.), Perspectives on activity theory (pp. 87106). Cambridge: Cambridge University Press.

Cole, M., \& Scribner, S. (1978). Introduction. In M. Cole, V. John-Steiner, S. Scribner, \& E. Souberman (Eds.), S. Vygotsky, Mind in society: The development of higher psychological processes (pp. 1-14). Cambridge, MA: Harvard University Press.

Dron, J. (2002). Achieving self-organisation in network-based learning environments. Unpublished doctoral dissertation, Brighton University, Brighton, UK.

Dron, J. (2006). Social software and the emergence of control. Paper presented at the 6th IEEE International Conference on Advanced Learning Technologies, Kerkrade, The Netherlands. Retrieved November 10, 2007, from http://www.cmis.brighton.ac.uk/staff/jd29/papers/ icalt2006.doc.

Dron, J. (2007). Designing the undesignable: Social software and control. Educational Technology \& Society, 10(3), 60-71.

Dron, J., Seidel, C., \& Litten, G. (2004). Transactional distance in a blended learning environment. ALT-J, 12(2), 163-174.

Engeström, Y. (1999). Activity theory and transformation. In Y. Engeström, R. Miettinen, \& R.Punamaki (Eds.), Perspectives on activity theory (pp. 19-38). Cambridge: Cambridge University Press.

Eskola, A. (1999). Laws, logics, and human activity. In Y. Engeström, R. Miettinen, \& R. Punamaki (Eds.), Perspectives on activity theory (pp. 107-114). Cambridge, Cambridge UniversityPress.

Garrison, R. (2000). Theoretical challenges for distance education in the 21st century: A shift fromstructural to transactional issues. International Review of Research in Open and DistanceLearning, 1(1). Retrieved November 10, 2007, from http://www.irrodl.org/index.php/irrodl/article/viewFile/2/22.

Goodfellow, R., Lea, M., Gonzalez, F., \& Mason, R. (2001). Opportunity and e-quality: Intercultural and linguistic issues in global online education. Distance Education, 22(1), 65-84.

Gorsky, P., \& Caspi, A. (2005). A critical analysis of transactional distance theory. The QuarterlyReview of Distance Education, 6(1), 1-11.

Gorsky, P., Caspi, A., \& Trumper, R. (2004). Dialogue in a distance education physics course. Open Learning, 19(3), 265-277.

Hillman D., Willis, D., \& Gunawardena, C. (1994). Learner-interface interaction in distance education: An extension of contemporary models and strategies for practitioners. The AmericanJournal of Distance Education, 8(2), 30-42.

Keegan, D. (1990). Foundations of distance education. London: Routledge. 
Kramarae, C. (2003). Gender equity online, when there is no door to knock on. In M.G. Moore \& W.G. Anderson (Eds.), Handbook of distance education (pp. 261-272). Mahwah, NJ: Lawrence Erlbaum Associates.

Leont'ev, A. (1978). Activity, consciousness, and personality. Englewood Cliffs, NJ: PrenticeHall.

Lowell, N.O. (2004). An investigation of factors contributing to perceived transactional distance in an online setting. Unpublished doctoral dissertation, University of Northern Colorado, Greeley.

Moore, M.G. (1972). Learning autonomy: The second dimension of independent learning. Convergence, 5(1), 76-87.

Moore, M.G. (1980). Independent study. In R. Boyd \& J. Apps (Eds.), Redefining the discipline of adult education (pp. 16-31). San Francisco: Jossey-Bass.

Moore, M.G. (1983). The individual adult learner. In M. Tight (Ed.), Education for adults (pp. 153-168). London, Croom Helm.

Moore, M.G. (1989). Three types of transaction. In M.G. Moore \& G.C. Clark (Eds.), Readings in distance learning and instruction (pp. 100-105). University Park, PA: The Pennsylvania State University.

Moore, M.G. (2007). The theory of transactional distance. In G. Moore (Ed.), Handbook of distance education (2nd ed., pp. 89-105). Mahwah, NJ: Lawrence Erlbaum Associates.

Moore, M.G., \& Kearsley, G. (1996). Distance education: A systems view. Belmont, CA: Thomson Wadsworth.

Moore, M.G., \& Kearsley, G. (2005) Distance education: A systems view (2nd ed.). Belmont, CA: Thomson Wadsworth.

Pruitt, D. (2005). Transactional distance and learner autonomy as predictors of student performance in distance learning courses delivered by three modalities. Unpublished doctoral dissertation, Tulane University, New Orleans, LA.

Saba, F. (1988). Integrated telecommunications systems and instructional transaction. The American Journal of Distance Education, 2(3), 17-24.

Saba, F. (2007). A systems approach in theory building. In G. Moore (Ed.), Handbook of distance education (2nd ed., pp. 43-55). Mahwah, NJ: Lawrence Erlbaum Associates.

Saba, F., \& Shearer, R. L. (1994). Verifying key theoretical concepts in a dynamic model of distance education. American Journal of Distance Education, 8(1), 36-59.

Sawchuk, P. H., Gawron, Z., \& Taylor, J. (2002). E-learning and union mobilization. Journal of Distance Education, 17(3), 80-96.

Shattuck, K. (2005). Glimpses of the global coral gardens: Insights of international adult learnerson the interactions of cultures in online distance education. Unpublished 
Doctoral dissertation, The Pennsylvania State University, University Park, PA.

Shin, N. (2001). Beyond interaction: Transactional presence and distance learning. Unpublished doctoral dissertation, Pennsylvania State University, University Park, PA.

Shin, N., \& Chan, J. K. Y. (2004). Direct and indirect effects of online learning on distance education. British Journal of Educational Technology, 35, 275-288.

Stein, D.S., Wanstreet, C.E., Calvin, J., Overtoom, C., \& Wheaton, J.E. (2005). Bridging the transactional Distance gap in online learning environments. American Journal of Distance Education, 19(2), 105-118.

Tolman, C.W. (1999). Society versus context in individual development: Does theory make a difference? In Y. Engeström, R. Miettinen, \& R. Punamaki (Eds.), Perspectives on activity theory (pp. 70-86). Cambridge: Cambridge University Press.

Toulmin, S. (1999). Knowledge as shared procedures. In Y. Engeström, R. Miettinen, \& R. Punamaki (Eds.), Perspectives on activity theory (pp. 53-64). Cambridge: Cambridge University Press.

Vygotsky, L.S. (1978). Mind in society: The development of higher psychological processes. Cambridge, MA: Harvard University Press.

Wagner, E.D. (1994). In support of a functional definition of interaction. The American Journal of Distance Education, 8(2), 6-29.

Wikeley, F., \& Muschamp, Y. (2004). Pedagogical implications of working with doctoral students at a distance. Distance Education, 25, 125-142.

Woods, R.H., \& Baker, J.D. (2004). Interaction and immediacy in online learning. International Review of Research in Open and Distance Learning, 5(2). Retrieved October 20, 2007, from http://www.irrodl.org/index.php/irrodl/article/view/186/268. 


\section{Figures}

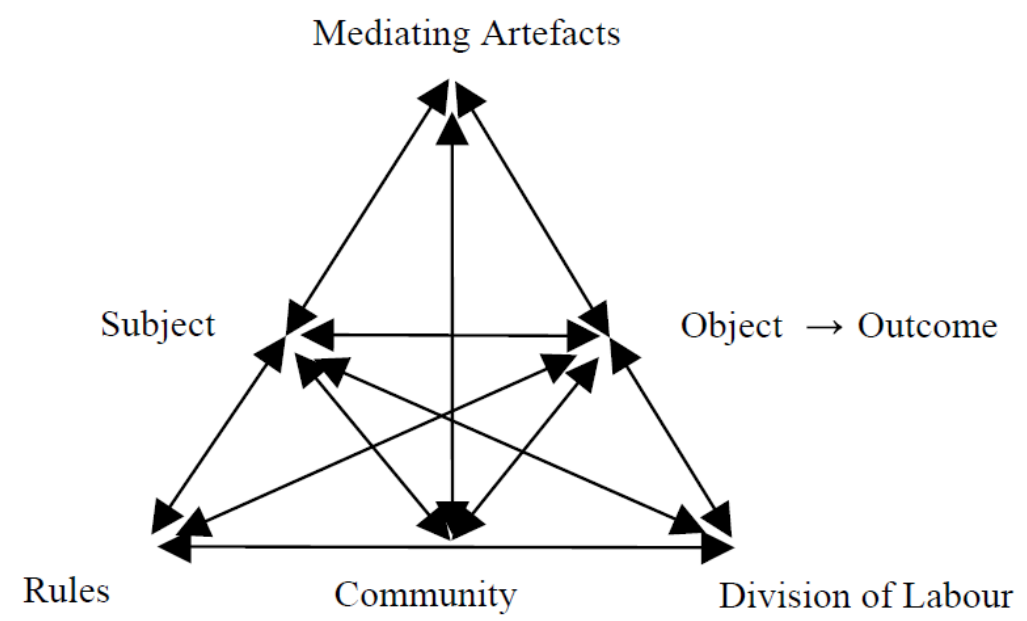

Figure 1. Engeström's (1999) model of an activity system.

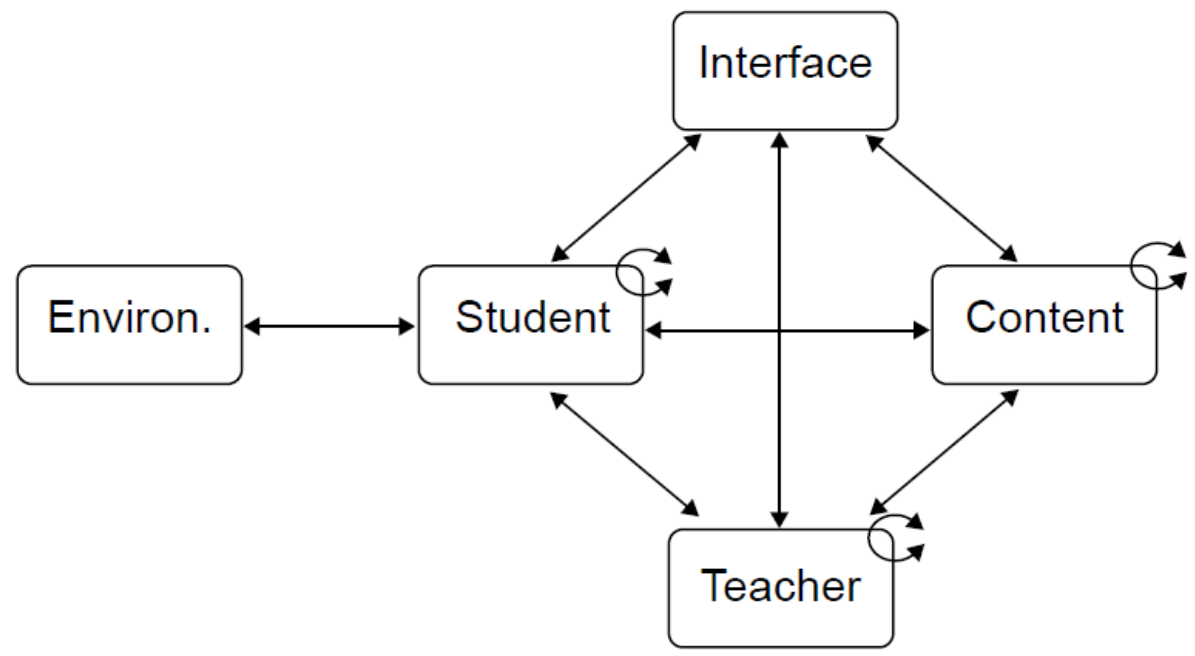

Figure 2. Modes of interaction in distance education. Adapted from Anderson and Garrison (1998), Hillman et al. (1994), and Burnham and Walden (1997). 


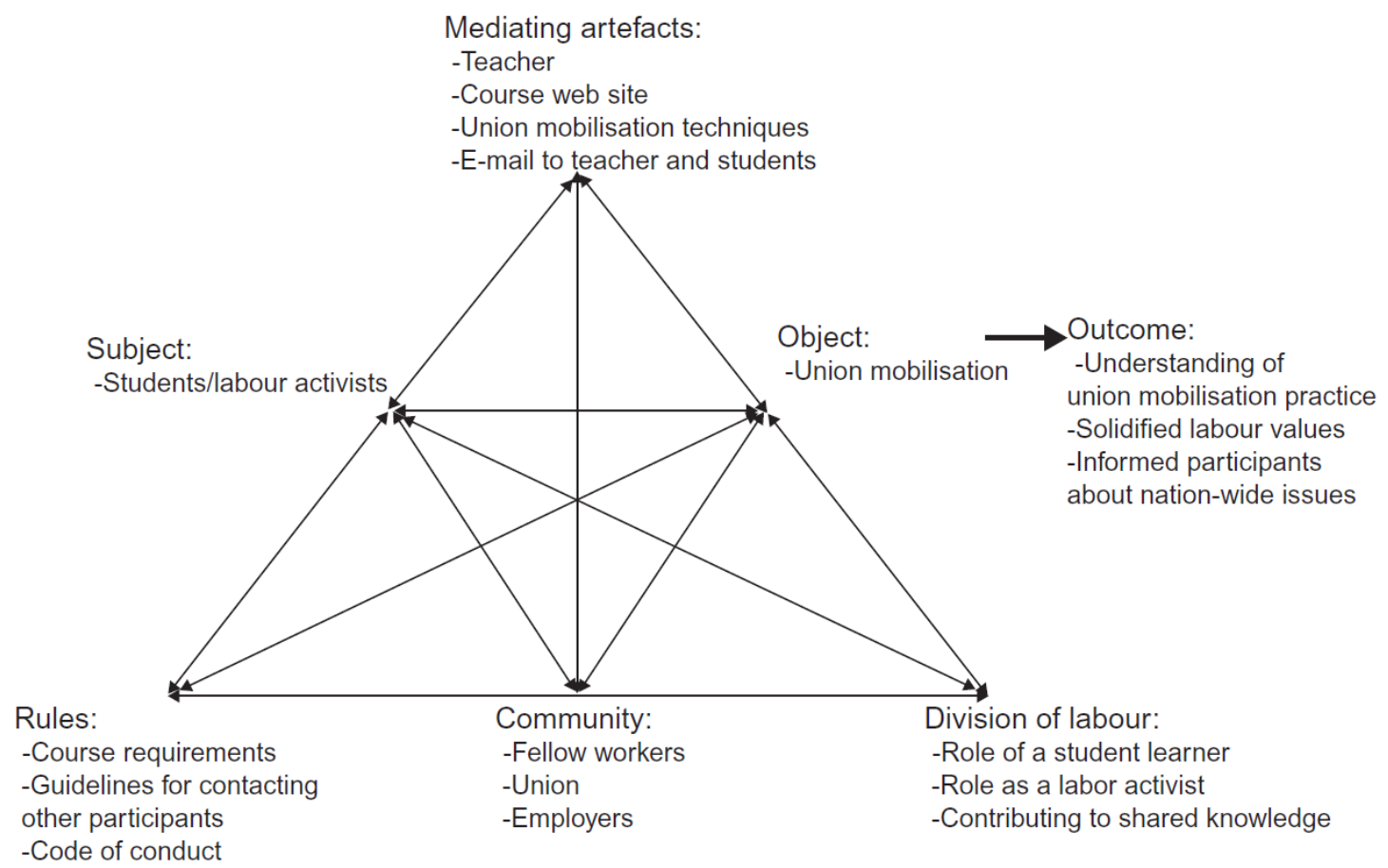

Figure 3. Model of an online educational activity system for labour activists. Adapted from Engeström (1999). 